\title{
JUDITE: NOME DE UMA HISTÓRIA RESIDUAL
}

\author{
Elizabeth Dias Martins ${ }^{1}$ \\ Mary Nascimento da Silva Leitão ${ }^{2}$
}

\begin{abstract}
Resumo: A personagem Judite, em Nome de guerra de Almada Negreiros, é a representação de uma imagem feminina ainda atrelada a preceitos de tempos remotos, principalmente medievais. Esse olhar voltado para reminiscências de outras épocas, em vigor na modernidade, é procedido à luz da teoria da residualidade (PONTES, 1999), que identifica traços de mentalidade do passado arraigados em obras literárias dos diversos períodos literários posteriores. Assim, a mulher vista da perspectiva do olhar masculino, bem como as nuanças de um perfil feminino engendradas na mente do homem e a relação fraqueza versus fortaleza como concepção estereotipada do feminino/frágil/inferior versus masculino/forte/superior, são alguns dos aspectos a discutir ao longo desse trabalho.
\end{abstract}

Palavras-chave: Perfil feminino; Residualidade; Medievo; Romance português

\section{JUDITE: THE NAME OF A RESIDUAL STORY}

\begin{abstract}
Judite, a character of Nome da guerra by Almada Negreiros, is the representation of a female image related to precepts of ancient times, particularly the Middle Ages. That glance towards vestiges of other times that are still in force in modernity is directed according to the theory of residuality (PONTES, 1999). That theory identifies traces of past mentality that are rooted in literary works of several subsequent literary periods. Therefore, the woman seen by male perspective, as well as the nuances of a female profile framed in the male mind and the relation weakness versus fortress as stereotyped conception of feminine/fragile/inferior versus masculine/vigorous/higher, are some of the aspects that will be discussed in this work.
\end{abstract}

Keywords: Female profile; Residuality, Middle Ages; Portuguese novel "ERA UMA VEZ uma rapariga chamada Judite. Mas o seu nome
verdadeiro não era Judite. Só às vezes, em ocasiöes muito intimas, é que ela
esteve quase para dizer tudo:
- Eu não me chamo Judite. Mas não digas nada a ninguém. O
meu nome verdadeiro é...
E calou-se."

(Almada,1997, p. 255)

Podemos afirmar que, para a obra de Almada Negreiros, há dois ângulos de análise possíveis através da teoria da Residualidade, corpus teórico com o qual temos trabalhado em

\footnotetext{
${ }_{1}$ Crítica e ensaísta. Doutora em Letras pela PUC-Rio. Professora Associada da Universidade Federal do Ceará (UFC).

${ }^{2}$ Doutoranda em Letras pela Universidade Federal do Ceará (UFC).
} 
nossas pesquisas ${ }^{3}$, o qual se pode sintetizar nas seguintes palavras de Roberto Pontes, sistematizador da referida teoria:

Quando falo de resíduo, digo remanescência; se pronuncio resíduo, refiro-me a sobrevivência. (...) resíduo é aquilo que remanesce de uma época para outra e tem a força de criar de novo toda uma obra, toda uma cultura. O residuo é dotado de extremo vigor. Não se confunde com o antigo. (PONTES, 2006, p.2-3)

Quanto às duas formas de abordagens na perspectiva da residualidade em Almada Negreiros, estas foram feições demonstradas no livro Do fragmento à unidade: a lição de gnose almadiana (MARTINS, 2013), tese de doutorado de uma das autoras do presente artigo.

Em primeiro lugar, temos aquela manifestada em formulações que equivalem às dos fundamentos e conceitos operacionais da teoria no tocante à compreensão das categorias tempo e espaço, que levam à constatação de ser o tempo unitário e as culturas híbridas. Quanto ao tempo, compreende-se que o presente e o futuro são constituídos de resíduos do passado que se manifestam de maneira recriada, cristalizada. Portanto, este é concebido como um todo, que se perfaz através da compreensão de que na cultura e na literatura tudo é residual. Assim, o "novo" vem a ser aquilo que é mais antigo. Ou seja, "Tudo quanto se passou no mundo, se passa e se passará," (ALMADA, 1997, p. 941).

São inúmeras as passagens, quer nos textos de caráter ensaístico, quer nos de criação, em que o modernista português deixa clara sua concepção de tempo unitário. Em "Reaver a ingenuidade: o mundo sensível" lemos:

O Tempo é Ato contínuo o Todo. O Tempo é feição do Todo. É unidade indivisível do Todo indivisível. Uma unidade do Todo, como o Todo.

Passado, presente e futuro é sempre o mesmo Todo de tempo: o passado é o Todo do Tempo, o presente é o Todo do Tempo, o futuro é o Todo do Tempo (ALMADA, 1997, p. 923).

Através dessa compreensão, Almada afirma trazer o homem preso ao presente à sombra do passado (ALMADA, 1997, p. 692). Levando-se em conta o encurtamento das distâncias e o contato cada vez maior entre os povos, temos que os indivíduos são cada vez mais produto da diversificação cultural em face da influência recíproca de todas as culturas. Tais afirmativas podem ser constatadas em textos como "Rosa dos ventos":

${ }^{3} \mathrm{O}$ termo residualidade foi empregado, inicialmente, por Roberto Pontes, no livro Poesia insubmissa afrobrasilusa. Rio de Janeiro-Fortaleza: Oficina do Autor/EUFC, 1999. 
Não foi por acaso que o meu sangue que veio do Sul se cruzou com o meu sangue que veio do Norte.

Não foi por acaso que o meu sangue que veio do Oriente se cruzou com o meu sangue que veio do Ocidente.

Não foi por acaso nada de quem sou agora.

Em mim se cruzaram finalmente todos os lados da terra.

A natureza e o tempo me valeram: séculos e séculos ansiosos por esse resultado um dia e até hoje fui sempre futuro.

Faço hoje a cidade do Antigo

e agora nasço novo como ao Princípio:

foi a Natureza que me guardou a semente

apesar das épocas e gerações.

cheguei ao fim do fio da continuidade

e agora sou o que até ao fim fui desejo:

o Centro do Mundo já não é no meio da terra

vai por onde anda a Rosa dos Ventos

vai para onde ela vai

anda por onde ela anda.

agora chego a cada instante pela primeira vez à vida

já não sou um caso pessoal

mas sim a própria pessoa.

(ALMADA, 1997, p. 219-220)

Nesse poema lemos que a constituição do homem é alicerçada na sua riqueza residual. Isto é possibilitado pelo entrecruzamento de tempo e espaço.

A segunda abordagem se dá pela constatação da presença de resíduos da mentalidade de períodos históricos, os mais diversos, próximos ou distantes, como o clássico, o medieval, o barroco e o romântico, bem pronunciados na obra do autor de Cena do ódio.

No romance Nome de guerra, vale a pena chamar atenção para a mentalidade ali detectada em relação ao papel da mulher, que remonta ao período do medievo. Ora, já no relato da criação do mundo, a mulher, segundo a mitologia hebraica, é vista como responsável pela perdição humana, por comer o fruto proibido da árvore do bem e do mal, e ainda incentivar Adão a fazer o mesmo (LINS, 1939, p.161).

Assim, pois, a teologia, por um lado, e, por outro, os depravadíssimos costume dos antigos, sobretudo depois de determinada conquista romana, conduziram os cristãos (os quais se preocupavam em regenerarse moralmente) a uma apreciação desfavorável da mulher, observando os monges que o diabo era sempre mais temível quando revestia a forma feminina (LINS, 1939, p.162).

A imagem que se fazia da mulher, durante longo período, foi tida como símbolo de sedução e perigo. Por esse motivo, sua invisibilidade e silêncio era regra indispensável para manter a ordem das coisas. Seria a "garantia de uma sociedade tranquila. Sua aparição 
em grupo causa medo. Entre os gregos é a stasis, a desordem. Sua fala em público é indecente" (PERROT, 2008, p. 16). Esse pensamento exposto por Perrot é equivalente ao que se lê na Bíblia sagrada, em passagem cujo intuito é pautar o comportamento feminino. Tomemos o texto sagrado:

Comportamento das mulheres - Quanto às mulheres, que elas tenham roupas decentes e se enfeitem com pudor e modéstia. Não usem tranças, nem objetos de ouro, pérolas, ou vestuário suntuoso, pelo contrário, enfeitem-se com boas obras, como convém a mulheres ser piedosas. Durante a instrução a mulher deve ficar em silêncio, com toda a submissão. Eu não permito que a mulher ensine ou domine o homem. Portanto, que ela conserve o silêncio. Porque primeiro foi formado Adão, depois Eva. E não foi Adão que foi seduzido, mas a mulher que, seduzida, pecou. Entretanto, ela será salva pela sua maternidade, desde que permaneça com modéstia na fé, no amor e na santidade (1Tm 2, 915).

De acordo com a visão de mundo cristã-medieval, a mulher é um ser subordinado e inferior. Isso ocorre porque se deve a Eva, segundo os clérigos, a origem do pecado original, responsável que é pela queda da humanidade e a perda do Paraíso edênico. Àquela época, a mulher, ao mesmo tempo, podia representar a personagem Eva, ou Maria, mãe de Deus, conforme fosse sua conduta. A primeira seria expressão da tentação e do pecado. A segunda, da pureza e da divindade. O louvor e a devoção à Virgem Maria têm início no século XI. Desde esta data, registra-se a invocação de Maria como advogada e intercessora dos homens; já a de Eva "foi muito mais precoce" e, segundo Le Goff (2011, p. 119-120), "desde muito cedo foi utilizada como imagem simbólica da Igreja", pois, por simbolizar Eva, esta instituição "participa, de certa forma do pecado original.” Leiamos o que escreve Le Goff:

A cristandade é dirigida por uma instituição não isenta do erro e do pecado, uma instituição falível, o que fica evidente no comportamento dos contemporâneos daquele período. [...] Para compreender o conteúdo dessa alegoria é preciso lembrar que o cristianismo medieval buscou na Bíblia constantemente referências, explicações para as realidades de seu tempo. Então, nisso é que se vai achar uma espécie de figura primitiva, primeira, se se quiser da mulher. A sociedade medieval, que não tinha o sentido da história, com naturalidade representou a Igreja nessa perspectiva eterna, a-histórica (LE GOFF, 2011, p. 120).

Eva foi a primeira mulher a ser contemplada nos textos bíblicos ${ }^{4}$. Sua representatividade no seio da Igreja levantou muitas discussões ao longo do tempo, especialmente no que condiz à superioridade masculina. Tomás de Aquino foi um dos que

\footnotetext{
${ }^{4}$ Referimo-nos ao Livro de Gênesis, desconsiderando a ordem em que a Bíblia foi escrita.
} 


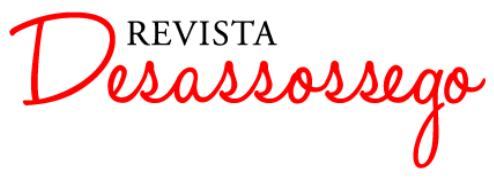

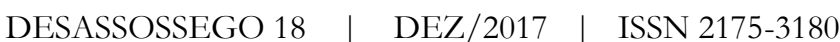

DOI: http://dx.doi.org/10.11606/issn.2175-3180.v9i18p30-41

admitiram a igualdade entre os sexos. Segundo ele, a mulher não foi criada de uma parte inferior nem superior do homem; portanto, não haveria motivos para a disseminação das diferenças. Esse pensamento valorizou a mulher, à época, tão inferiorizada (LE GOFF, 2011, p.122). E resíduo dessa mentalidade é o modo como está representada a personagem almadiana de Nome de guerra.

Da alusão inicial à Judite bíblica, ao que temos no romance, não vai muita distância no que toca ao aspecto antitético da fraqueza versus fortaleza. Assim como à força de Holofernes se opõe a fraqueza de Judite, em seguida dá-se a conversão da fraqueza em força e desta em fraqueza. Basta considerar o episódio em que Judite enfrenta D. Jorge, ameaçando-o com uma garrafa. A passagem ganha maior significado dada a exclamação com que se inicia:

- Ó filho! Já me tiraram o medo há muito tempo!

Com uma rapidez vertiginosa deitou a mão à garrafa e, de pé, ficou com o gesto decidido de lha esmigalhar na testa. Ele não esboçou uma única defesa. Limitou-se a não tirar os olhos de cima dela.

- Lá por seres o d. Jorge!...

Era uma franganita para o d. Jorge, mas naquele repente estava tão decidida que era a maior de todos quantos iam no carro (ALMADA, 1997, p. 269).

Porém esta superioridade momentânea é desfeita nas linhas seguintes quando se lê que apenas os homens entram na contagem dos passageiros. As mulheres, naquele contexto, são seres inexistentes diante da presença masculina. Eis o trecho: “- Bravo! - fez com entusiasmo o d. Jorge, e para seguir no seu pensamento bateu no ombro do motorista e disse-lhe: - Eu não te dizia? Cá só vão dois passageiros, o resto é palha” (ALMADA, 1997, p. 269).

A propósito dessa relação de fraqueza versus fortaleza, podemos retomar as palavras de Le Goff e Truong (2006) em Uma história do corpo na idade média:

A subordinação da mulher possui uma raiz espiritual, mas também corporal. "A mulher é fraca" observa Hildegard de Bingen no século XII, "ela vê no homem aquilo que pode lhe dar força, assim como a lua recebe sua força do sol. Razão pela qual ela é submetida ao homem e deve sempre estar pronta para servi-lo". Segunda e secundária, a mulher não é nem o equilíbrio nem a completude do homem. Em um mundo de ordem e de homens necessariamente hierarquizado, "o homem está em cima, a mulher está em baixo", escreve Christiane Klapisch-Zuber (LE GOFF \& TRUONG, 2006, p. 52). 


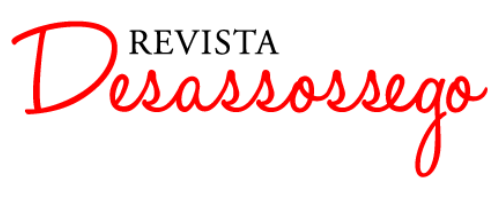

\begin{tabular}{l|l|l} 
DESASSOSSEGO 18 & DEZ/2017 & ISSN 2175-3180
\end{tabular}

DOI: http://dx.doi.org/10.11606/issn.2175-3180.v9i18p30-41

Referida ideia confirma a presença dos resíduos medievais relativamente ao imaginário feminino. A força de Judite não pode ser reconhecida por conta de uma mentalidade que está adstrita à figura masculina. Traço de uma mentalidade de grande vigor presente representativamente em diferentes obras literárias modernas.

Judite, prostituta com quem Antunes trava relacionamento amoroso, ocupa no romance almadiano, escrito em plena vigência do primeiro modernismo português, o lugar convencional destinado às meretrizes na sociedade medieval. Considerada minoria na Idade Média, juntamente com os sodomitas, os hereges, os judeus e os leprosos, elas, a exemplo dessas demais frações, eram vistas como desvios dos preceitos cristãos, portanto, estavam relacionadas ao pecado e, por consequência, ao Diabo.

Devido ao envolvimento da mulher prostituta na atmosfera de pecado e de perigo, esta espécie de profissional era mesmo considerada, ao modo das outras minorias, um agente demoníaco, próximo da carnalidade, personificando a tentação e o pecado, principalmente se levarmos em conta que o medievo foi período áureo para a Igreja Católica, no qual Roma exercia grande poder político e econômico sobre a sociedade, que deveria seguir os preceitos por ela determinados. Todavia, vale ressaltar, a prostituição nem sempre foi vista sob a perspectiva cristã:

A prostituição é um sistema antigo e quase universal, mas organizado de maneira diferente e diversamente considerado, com status diferentes e diferentes hierarquias internas. A reprovação da sociedade é bastante diversa. Depende do valor dado à virgindade e da importância atribuída à sexualidade. As civilizações antigas ou orientais não têm a mesma atitude que a civilização cristã, para a qual a carne é a sede da infelicidade e a fornicação é o maior pecado. Figura complexa, Maria Madalena encarna ao mesmo tempo a sedução, a pecadora e a doçura do arrependimento. Ela introduz no universo austero da santidade uma doçura estranha. (PERROT, 2008, p.78)

O campo de guerra permanentemente disputado entre Bem e Mal, Deus e Diabo, Cristo e Anticristo, anjos e demônios, todos, caracterizadores da concepção de mundo maniqueísta em voga na Idade Média, é o que podemos constatar nas páginas do romance em análise. Entre as personagens Maria e Judite há universos e concepções semelhantes a pontuar o imaginário relativo a Ave e Eva.

Basta aludir ao fato de ser o ambiente citadino equivalente ao do Inferno, conforme descrito por d. Jorge e Judite. E pelas impressões de Antunes a vida na cidade "era um daqueles monstros da Idade Média com imensos tentáculos cheios de ventosas para chupar 


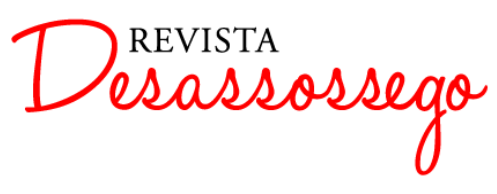

por uma vez os que andam perdidos do conjunto" (ALMADA, 1997, p. 272). Enquanto isso, a província se liga à imagem do presépio de Natal. Ou seja, a cidade se aproxima do diabólico, a província se acerca do sagrado.

Quanto a Maria e Judite, duas imagens vinham à tona quando Antunes pensava sobre o amor: a primeira, singela e vestida, que dormia um sono branco; a outra nua, de carnes sequiosas, a morder e a cuspir, estava com as garras prontas para se defender de todos. A primeira ligada ao ambiente de luz da província é Maria, representação ficcional conforme o paradigma da Mãe Santíssima, parâmetro dos preceitos cristãos, modelo de mulher segundo a Igreja; a outra é Judite, mulher notívaga, admiradora das trevas. Consideremos duas passagens do romance em que se constata um crepuscularismo maligno:

Ela foi adiante para ensinar. No segundo andar ele ficou à porta e ouviuse o fechar das janelas...

(...)

E tão afeito estava àquilo tudo que o Antunes nem reparava que havia precisamente cinco dias que nunca mais tornara a ver a luz do sol, que as portas de dentro das janelas nunca mais se abriram, que viviam de noite e dormiam de dia. (ALMADA, 1997, p. 293/296)

Ainda no que se refere à mentalidade medieval relativa ao sexo, às minorias, ao pecado, ao diabo e sua aproximação residual com a visão de mundo entrevista no romance modernista ora comentado, cabe aludir às passagens nas quais Antunes vivia o drama de relacionar-se com a prostituta. Ao debater-se consigo, Antunes parecia lutar contra o que seria verdadeira agressão à sua pessoa. A espécie de outro eu que estava prestes a aflorar era chamado por ele mesmo de "besta", uma das designações dicionarizadas de demônio. E ele o invocava como se chamasse uma entidade propícia a certas práticas condenadas pela educação recebida de seus pais na distante província:

No dia seguinte, ao acordar, recordou a véspera e ficou zangado consigo. Descompunha-se em voz alta, como se ele fosse uma segunda pessoa ali no quarto:

- Tu queres que a besta acorde ou não queres?! Se queres, não há cá juízos, porque espantas a besta! (ALMADA, 1997, p. 276)

A decisão tomada pelo protagonista de relacionar-se com Judite o leva a assumir a fisionomia monstruosa e o apetite sensual incontrolável da "besta" invocada por ele. Nesta passagem, o narrador nos faz ver que a consciência de haver transgredido um preceito moral faz Antunes sentir pavor da sua metamorfose ética, na imagem, como que diabólica, 


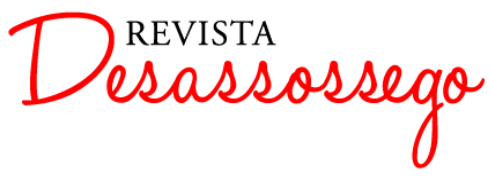

refletida no espelho. Sendo este o modo do castigo, a manifestação do pecado, tudo se dá tal qual a Igreja pregava aos cristãos no período medieval:

De repente, o Antunes viu diante de si uma cara horrível, espectral, parada, que não tirava os olhos de cima dele. Era a sua própria cara que estava no espelho. Ele e a sua imagem eram como duas estátuas de pedra voltadas uma para outra. Nunca o Antunes sentira na sua vida uma impressão mais desagradável do que aquela! A sua própria fisionomia enchia-o de pavor: a cara inerte sofria sem dor, desejava sem prazer, não chorava, não ria, era de pedra como as estátuas, fria como o espelho. Sentia ganas de esbofetear-se para fazer acordar as expressões. Ferir-se, golpear-se, abrir as fontes e as artérias para ver se era ardente e vermelho o sangue que lhe batia no coração!

E o Antunes falava para a sua imagem no espelho:

- Ó máscara, ri, chora, fala, grita, sofre, goza, canta, ama, mata, odeia, vive ou morre!... - E a sua imagem no espelho continuava parada, espectral, horrível! (ALMADA, 1997, p. 278)

Mas esta mentalidade relativa à aproximação das minorias com o universo satânico se estende principalmente a Judite. Não foi difícil para Almada, artista plástico visivelmente atraído pela arte cubista, transformá-la num ser cujas formas se assemelham às de um monstro. "Quando pequena era miúda, muito raquítica, cheia de tumores por todo o corpo" (ALMADA, 1997, p. 298); já crescida, a jovem se torna espectral e diabólica, a descrição é de aspecto caricaturesco e o hibridismo sugerido beira o grotesco. Isto tudo escrito pela pena da ironia... A passagem é longa e vale a pena não fazer cortes. Se não, vejamos:

Sem dúvida, a Judite era um achado raríssimo de cor e forma. (...). Tinha um pescoço horrível, sem ligação da nuca com as costas. Uma cova em triângulo entre as omoplatas e a falha do pescoço. E aqui a cor era ordinária. Porém, a nuca perfeita de redondeza, nem saliente, nem retraída. O tronco era uma verdadeira maravilha. Era todo o segredo da sua formosura. Os seios hediondos, partidos, duas excrescências inutilizadas. O busto curto, mas sólido. Os ombros grandes e largos, levemente subidos. Os braços apertavam desde o ombro até ao pulso por uma forma ridícula e sem distância. As ancas cerradas, entre menina e mulher. A linha dos ombros mais larga do que a das ancas, conforme a robustez do tronco. O ventre, bem-posto, era contudo mais admirável do que formoso, mais escultural do que atraente. O umbigo, o sexo, as virilhas, era tudo infantil, inocente. As coxas é que rompiam audaciosas. A cor das coxas era clara e a do ventre incomparavelmente menos clara. Via-se que era filha de uma pessoa muito branca e de outra bastante morena. Mas a mistura não estava bem-feita: a sua pele ia desde o mármore rosa-pálido até ao tijolo sujo. As costas, genialmente bem divididas por um único vinco, firme, vertical, helénico, separando duas metades simétricas, amplas, até aos rins longos. Umas nádegas de rapaz. As pernas, se tinham algum atractivo, não pertenciam contudo à maravilha daquele tronco, esse acaso feliz da natureza. As barrigas das 
pernas, grosseiras, saltimbancanescas. Os joelhos estropiados. Os pés horríveis, o pior de tudo juntamente com as mãos. Estas davam a impressão de não fecharem, desajeitadas, incompletas, mal terminadas, falhas de paciência. Os dedos não se punham direitos. As unhas roídas até para lá do meio. Enfim, as extremidades péssimas. Dir-se-ia que a desordem da sua vida ia dar cabo daquela obra-prima da natureza e começara já a sua destruição pelas extremidades. A cabeça também era incompleta, mas tinha qualquer beleza que se ligava com o tronco. A testa pequeníssima ao alto e ao largo. Bons cabelos lisos, mal começados na frente, com remoinhos. As orelhas pobres, minúsculas e engraçadas. Uma boca ingénua, sem a sua maldade, e um jeito pândego ao canto da direita. Autêntica boca de rua. Bons dentes, curtos, já separados, e as gengivas gastas. Os olhos míopes não davam o encanto que prometiam. $\mathrm{O}$ nariz pequeno e perfeito. $\mathrm{O}$ perfil desde o fim da testa, com a boca fechada, até ao busto, era formidável de inteireza e de carácter meridional, peninsular, português. Bastante viril e sem por isso ser masculino. (...)

Se a Judite fosse uma estátua, podia ser aproveitada como exemplo de beleza, depois de sofrer algumas mutilações (ALMADA, 1997, p. 319$320)$.

Historicamente, há uma preocupação com a beleza observada desde a Antiguidade Clássica. Umberto Eco, em História da beleza, cita um canto de núpcias de Cadmo e Harmonia, realizado em honra dos esposos, pelas musas em Tebas: "Quem é belo é caro, quem não é belo não é caro" (ECO, 2010, p. 37). O valor atribuído à beleza, neste caso, equivale ao valor dado à imagem da Judite na minuciosa descrição depreciadora da personagem. No trecho de Almada, é de chamar a atenção o tom machadiano implícito na "crueldade" irônica da descrição acima, desde a primeira frase. Ressalte-se o anúncio anterior à descrição, pois este gera no leitor uma expectativa que vai sendo frustrada através da ironia fina que há no contraste entre o que se imagina e o real detalhamento das formas e da constituição da personagem: "Judite era um achado raríssimo". A ironia almadiana do trecho é construída sobre o contraste entre um "achado" que em vez de ser algo raro, de grande valor, é "horrível", "hediondo", "grosseiro" e "desajeitado".

O desfecho de puro sarcasmo soa tal qual tiro de misericórdia, ou seja, Judite "podia ser [...] exemplo de beleza", “depois de sofrer algumas mutilações". Temos na passagem um exemplo de humour, equivalente a passagens das narrativas machadianas como esta do conto "Um homem célebre" em que a ironia se organiza sobre um oximoro:

- Não, nem feia, assim, assim. Ouvi dizer que ele se enamorou dela, porque a ouviu cantar na última festa de S. Francisco de Paula. Mas ouvi também que ela possui outra prenda, que não é rara, mas vale menos: está tísica. (ASSIS, 1962: p. 500) 


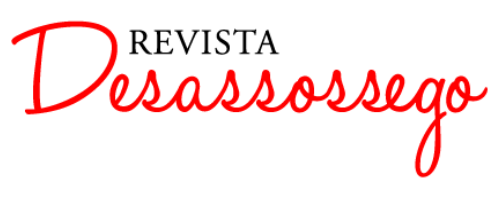

Recursos irônicos como estes empregados por Machado em suas narrativas e aqui igualmente flagrados no romance de Almada Negreiros, não poderiam ter melhor justificativa do que a dada neste trecho de Kierkegaard:

A ironia pode ainda mostrar-se de uma maneira mais indireta através de uma relação de oposição, quando ela dá preferência às pessoas mais simples e mais limitadas, não para burlar-se delas, mas sim para escarnecer dos homens sábios. (KIERKEGAARD, 1991: 218)

Espectral, monstruosa, é Judite; e o são ainda todos os que frequentam o clube de mulheres, de jogos e de danças, de acordo com o que se lê no capítulo "Uma descrição de determinadas pessoas que mais parece uma lista de peças de refugo", seção que sinaliza a despedida de Antunes daquele ambiente representativo para ele de uma espécie de iniciação para a vida, ou programa ritual iniciático. Após este momento, um passeio com Judite ao lado de amigas levou-o à "Boca do Inferno" (ALMADA, 1997, p. 330). E, curiosamente, como se estivesse vivendo a experiência do Purgatório, Antunes sai dali e toma caminho oposto ao das trevas, vai literalmente para cima, e termina o romance de "braços estendidos para fora da janela por cima dos telhados" de uma água-furtada "aberta para o ar" (ALMADA, 1997, p. 356-357).

Eis que por essa imagem o autor nos revela um Antunes libertado do universo de “trevas" que o ligava a Judite. Restava, a partir de então, exercer seu livre-arbítrio. Porém, cabe aqui uma ressalva quanto à personagem Judite que foi nada, ou "palha" no dizer de D. Jorge, passando a representar no final do romance a passagem, ou a porta para a realidade, para o processo de epifania de Antunes. E não foi a dela própria porque em sua mentalidade estava arraigada a ideia de ser pelos outros, ou mais precisamente, pelo outro afetivo, pelo homem:

Toda a gente faz de mim uma coisa e eu sou outra muito diferente. A Judite é isto, a Judite é aquilo, e não é nada disso. [...]Procedia, é claro, ainda à maneira antiga, mas já não era por querer, como dantes. Ela própria confessava ao Antunes: "Eu sou muito torta!... Mas tu deves ensinar o que eu hei-de fazer. Tu és o homem. Não me deixes fazer o que me vem à cabeça, que são tudo asneiras. Mostra que tens força e sabes o que queres!...” [...] Por fim, a confusão passou a realidade, e a Judite estava na verdade mudada: já não era uma Judite qualquer, era a Judite do Antunes. (ALMADA, 1997, p. 293-309,310).

Assim se conclui nossa análise e, com este trabalho, chegamos mais uma vez à constatação de haver Almada, bem como os demais companheiros de percurso em Orpheu, 


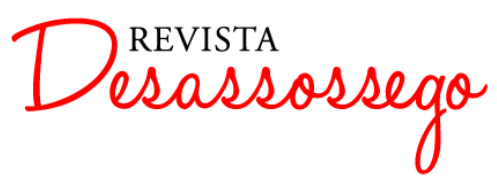

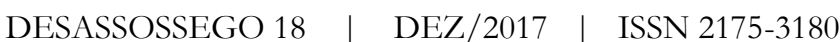

DOI: http://dx.doi.org/10.11606/issn.2175-3180.v9i18p30-41

realizado obras a partir da força de resíduos que se encontram em nossa mentalidade, prontos para recriação pelo processo estético da cristalização.

As imagens femininas, identificadas na obra do modernista português, dão exemplos da persistência de modos de ser medievais na modernidade. E embora a história da mulher passe por um processo de mudanças e conquistas femininas, principalmente no que concerne à independência frente ao homem, há elementos que continuam vivos e atuantes na sociedade. Desse modo, é comum observar-se a relação fraqueza versus fortaleza atribuída respectivamente ao sexo feminino e masculino. Trata-se de um jogo de contrários a atender não só às diferenças físicas, mas às psicológicas.

Quanto ao aspecto físico da mulher, sempre foi assunto bem discutido. Durante muito tempo esta foi vista como ornamento, como se suas ideias não merecessem respaldo. Somente a beleza era motivo de interesse. Trata-se de uma época em que a sociedade era regida exclusivamente por homens. Por isso, não à toa, foi corriqueira a ideia da mulher relacionada ao pecado.

A imagem de Judite resgata todo esse desvio de perspectiva que não ficou no passado. Ela apenas enfatiza a presença de resíduos que sobrevivem, não por uma tradição, mas por pensamentos ideológicos arraigados na mentalidade da sociedade moderna.

\section{Referências bibliográficas}

ALMADA NEGREIROS, José de. Obra completa. Rio de Janeiro: Aguilar S.A., 1997.

ASSIS, Machado de. Obra completa. Rio de Janeiro: Aguilar, 1962.

BÍBLLA SAGRADA. Edição Pastoral. Paulus, São Paulo: 1990.

ECO, Humberto. História da Beleza. [trad. Eliana Aguiar]. Rio de Janeiro: Record, 2010.

KIERKEGAARD, Søren Aabye. O conceito de ironia: constantemente referido a Sócrates. trad. Álvaro Luiz Montenegro Valls. Petrópolis: Vozes, 1991.

LE GOFF, Jacques. Uma longa Idade Média. [trad. Marcos de Castro]. Rio de Janeiro: Civilização Brasileira, 2011.

LE GOFF, Jacques. \& TRUONG, Nicolas. Uma bistória do corpo na Idade Média. [trad. Marcos Flamínio Peres]. Rio de Janeiro: Civilização Brasileira, 2006.

LINS, Ivan. A Idade Média: a cavalaria e as cruqadas. Rio de Janeiro: Coeditora Brasilica: 1939. 
MARTINS, Elizabeth Dias. Do fragmento à unidade: a lição de gnose almadiana. Fortaleza: EDUFC, 2013.

PERROT, Michelle. Minha história das mulheres. [trad. Angela M. S. Corrêa]. São Paulo: Contexto, 2008.

PONTES, Roberto. Poesia insubmissa afrobrasilusa. Rio de Janeiro-Fortaleza: Oficina do Autor/EUFC, 1999.

Entrevista sobre a Teoria da Residualidade, com Roberto Pontes, concedida à Rubenita Moreira, 05 e 14 de jun. 2006. Fortaleza: (mimeografado), 2006.

Data de recebimento: 30/04/2017

Data de aprovação: 22/12/2017 